TITLE PAGE

\title{
Are area-level measures of employment associated with health behaviours and outcomes?
}

\author{
Hannah Badland ${ }^{1}$, Allison Milner ${ }^{1,2}$, Rebecca Roberts ${ }^{1}$, Billie Giles-Corti ${ }^{1}$
}

\author{
Corresponding author \\ Dr Hannah Badland \\ McCaughey VicHealth Community Wellbeing Unit \\ Melbourne School of Population and Global Health \\ The University of Melbourne \\ Level 5, 207 Bouverie Street \\ Parkville \\ Victoria 3010 \\ Australia \\ Email: hannah.badland@unimelb.edu.au \\ Telephone: +61 383440943

\section{Authors' affiliation} \\ ${ }^{1}$ McCaughey VicHealth Community Wellbeing Unit, Melbourne School of Population and \\ Global Health, The University of Melbourne, Melbourne, Australia \\ ${ }^{2}$ Work, Health, and Wellbeing Unit, Population Health Strategic Research Centre, School of \\ Health and Social Development, Deakin University, Melbourne, Australia
}

\section{MAIN TEXT}

\section{INTRODUCTION}

Accessible employment suited to residents' needs is an important equity issue and social determinant of health and wellbeing. Higher levels of area-level unemployment are positively associated with area-level mortality rates, independent of individual-level socioeconomic factors, such as income and education, and this trend holds across high income countries (van Lenthe, Borrell et al. 2005). Living in an area of high unemployment increases feelings of job insecurity for those employed (Milner, Kavanagh et al. 2013) as well as an individual's time spent being under-employed or unemployed (Korsu and Wenglenski 2010). Other research shows that, independent of household income, those living in neighbourhoods of concentrated disadvantage are more isolated and have fewer social networks available to them (Baum, Ziersch et al. 2009, Warr, Feldman et al. 2009). While having employment opportunities available within the residential neighbourhood is not essential in itself; the location of employment is nevertheless 
important. For example, longer distances spent commuting to and from employment has been negatively associated with walking (Brownson, Boehmer et al. 2005), community cohesion (Jackson 2003); longer time spent commuting has been negatively associated with time spent with family (Wilson 2000), and positively associated with obesity risk (Frank 2004, Palmer 2005), blood pressure (Kluger 1998), and stress (Van Rooy 2006).

A balanced jobs-housing ratio (being between 0.8 and 1.2 ) within a region has the potential to shorten commute journeys, provide active travel opportunities (e.g. walking, cycling), and reduce peak-period traffic congestion and air pollution exposure (Cervero and Duncan 2006). For example, earlier work has shown those living and working in areas with a balanced jobs-housing ratio had $29 \%$ shorter commute journeys to work compared with those whose jobs were located in less balanced areas (ratio $<0.8$ or $>1.2$ ) (Frank and Pivo 1995). Having access to a suitable job within four miles from home has been regarded as an effective strategy for reducing vehicle miles travelled (Cervero and Duncan 2006). Notably, the spatial distribution of unemployment (i.e. the jobs-housing ratio) across a city has been found to be more strongly associated with mortality than the absolute level of unemployment (van Lenthe, Borrell et al. 2005). Accordingly, calls have been made for policy-makers to develop strategies to more co-locate housing, workplaces, and retail (Cervero and Duncan 2006). Policies designed to improve regional jobs-housing balance can also help reduce inequity by potentially providing incentives for people to relocate to areas closer to employment; this could have a disproportionate benefit for low income, single-working households (Levine 1998), as well as reducing 'excess commuting time' (and associated negative health consequences), which is more prevalent in low income workers (Schleith and Horner 2014).

Despite this evidence outlining the benefits of local employment opportunities, the average distance and time taken to access workplaces has been steadily increasing in developed countries (Cervero and Duncan 2006, Lyons and Chatterjee 2008), and more so for lower income workers (Schleith and Horner 2014). UK data suggest that one in ten people now spend at least two hours per day commuting to and from the workplace, with men's commute journeys being longer than women's journeys (Lyons and Chatterjee 2008). However, the health 
implications of commuting stress exposure over time have received little attention in the literature. One study by Palmer (Palmer 2005) identified fewer bouts of depression for those commuting less than 45 minutes to work, compared with those who commute for longer periods of time. Other research has shown that longer private vehicle commuting times have been negatively associated with life satisfaction (Stutzer and Frey 2004) and physical activity accumulation (Wen, Orr et al. 2006), and positively associated with risk of obesity (Frank, Andresen et al. 2004, Wen, Orr et al. 2006).

This paper seeks to provide evidence on the health benefits of being able to access local employment in the Australian metropolitan context. Such an ambition falls within the remit of providing the evidence to create more liveable cities. Liveability is a concept used throughout urban planning and policy in Australia (Western Australian Planning Commission and Department for Planning and Infrastructure 2009, State Government Victoria 2014) and internationally (Colantonio and Dixon 2011, Norris 2014). In our recent work we have conceptualised liveability through a social determinants of health lens (Badland, Whitzman et al. 2014), defining it as 'safe, attractive, socially cohesive and inclusive, and environmentally sustainable; with affordable and diverse housing linked to employment, education, public open space, local shops, health and community services, and leisure and cultural opportunities; via convenient public transport, walking, and cycling infrastructure' (Lowe, Whitzman et al. 2013). Creating a set of spatial indicators of attributes that contribute to liveability can assist in benchmarking, monitoring and evaluating urban environments. This paper forms part of wider project to measure and assess the health impact of liveability. It uses Australian data to create and test a set of spatial measures of urban employment (Badland, Davern et al. in press) with population health behaviour and outcome data. This research focuses on the urban context within Australia, as $85 \%$ of Australian jobs are located in urban settings (Australian Bureau of Statistics 2011).

\section{Research aim}

The pathways for how area-level measures of employment might influence health and wellbeing behaviours and outcomes are largely unknown. We now have an 
opportunity to create and test local- and suburb-level spatial measures of employment (local employment and mode access to employment) and pathways that we have hypothesised to be associated with health and wellbeing. Such work will provide evidence to policy-makers that can help build the argument about which area-level attributes are needed to support local urban employment across a region. Accordingly, the aim of this study was to create and test direct and pathway associations between selected local- and suburb-level spatial measures of employment with health and wellbeing behaviours and outcomes in the Australian urban context.

\section{METHODS}

\section{Employment conceptual framework development}

An employment conceptual framework was developed using a social determinants of health lens (Badland, Davern et al. in press). The more upstream (e.g. neighbourhood attributes) and more downstream (e.g. behaviours, intermediate outcomes) determinants of urban employment were identified and mapped in relation to long-term outcomes of interest (e.g. chronic conditions, mental health, sense of control) based on existing evidence (Theorell 2000, van Lenthe, Borrell et al. 2005, Strategic Review of Health Inequalities in England post-2010 2010) (see Figure 1). The full employment conceptual model is presented in Figure 1, with the grey boxes indicating the selected pathways that could be tested in this study, as we were able to access the appropriate data to populate and examine these pathways.

\section{Insert Figure 1 about here}

\section{Neighbourhood-level spatial measures}

Based on the evidence, three main neighbourhood-level attributes that influence urban employment were hypothesised to be important. These were: 1) local employment; 2) mode access to employment; and 3) neighbourhood employment level (Figure 1). However, in this study, we were only able to examine 'local 
employment' and 'mode access to employment' due to lack of suitable behavioural and outcome data.

For the two neighbourhood-level attributes investigated, four neighbourhood-level spatial measures of urban employment were identified and developed (see Table 1). All spatial data were taken from the census collection undertaken in 2011 (Australian Bureau of Statistics 2011), and were made available for analysis at the SA1 ( 400 persons / area) or SA3 ( 30,000 - 130,000 persons / area) administrative units. We chose to use two different scales. We regarded finergrained data (i.e., SA1) as being more appropriate for studying neighbourhood effects in an urban context. Smaller units can be aggregated to larger regional administrative units if required (Kwan 2012), and localised pockets of employmentrelated disadvantage can be identified. The SA3 level was considered to be an appropriate size for which local employment opportunities could be anticipated in an urban setting, and also reflects a commute distance readily accessible by active travel or public transport (Badland, Schofield et al. 2007). For simplification purposes, for the remainder of the paper SA1s are referred to as the 'local area' and SA3s are referred to as the 'suburb'.

\section{Insert Table 1 about here}

\section{Local employment}

Respondents recorded their employment location postcode when completing the 2011 census. Subsequently, the Australian Bureau of Statistics (ABS) provided customised data to calculate the percentage of adults in each local area who lived and worked in their residential suburb on census day (NB: workplace postcodes were not made available). For respondents' local areas, the proportion that both lived and worked within the same suburb was calculated. A binary measure of 'lower' or 'higher' levels of local employment ( $1=$ lower, 2 = higher) was created for the sample based on the median split.

Area-level travel mode to employment 
Commute mode to work on the day of the census was collected in the 2011 census. Responses were aggregated into three categories: private vehicle (i.e. car driver, car passenger, motorcycle, taxi); public transport (i.e. bus, train, tram, ferry); and active travel (i.e. walking, cycling, running). The ABS made these data available at the local area level. Each transport mode (i.e. private vehicle, public transport, active travel) was divided by the total number of employed adults commuting to work in the local area. This provided local area employment travel mode prevalence. Binary measures of 'lower' or 'higher' levels of work-related private vehicle, public transport, and active travel $(1=$ lower, $2=$ higher $)$ were created based on the median splits of the survey sample.

\section{Individual-level measures}

Demographic and health behaviour and outcome data were sourced from the 2011 VicHealth Indicators Survey. This self-report population health survey assesses a range of social determinants of health and community wellbeing factors in adults $(\geq$ 18 years) residing in Victoria, Australia. The survey was conducted across the 79 Victorian Local Government Authorities (LGA) using computer assisted telephone interviews. Overall, there were 25,075 participants with geo-coded data drawn from across Victoria (overall response rate 53.5\%). As this research is focussed on urban employment, we applied a combined measure of the Sections of State (Australian Bureau of Statistics 2011) and Metropolitan Boundary (State Government Victoria 2014) classifications to identify and select participants who lived in metropolitan Melbourne. Those living in non-urban, non-metropolitan areas were excluded ( $n=$ $15,580)$.

Three variables were used to populate the 'behaviours', 'intermediate outcomes', and 'long-term outcomes' components to test the two theoretical pathways highlighted in the conceptual framework (Figure 1).

Behaviour: Time spent commuting was self-reported as the total number of minutes taken on a typical day getting to and from work. A binary measure of 'lower' or 'higher' time spent commuting ( $1=$ lower ( $\leq 45$ minutes), $2=$ higher $(\geq 46$ minutes) was created based on the median split of the survey sample. 
Intermediate outcome: Sedentary behaviour was assessed by the selfreported number of minutes spent sitting for all purposes on a typical weekday (including driving, working at a desk or computer, reading, watching television, and playing computer games). A binary measure of 'lower' or 'higher' time spent sitting ( 1 = lower ( $\geq 360$ minutes), 2 = higher ( $\geq 361$ minutes $)$ ) was created based on the median split of the survey sample.

Long-term outcome: Chronic conditions were assessed through self-rated health (5-point likert scale; $1=$ excellent, $5=$ poor (since reverse coded)). Participants were recoded into a binary measure of 'poorer' or 'better' self-rated health $(1=$ poorer (poor + fair $), 2$ = better (good + very good + excellent $))$. Self-rated health is predictive of overall mortality and morbidity and is stable across the socioeconomic spectrum (Kaplan and Camacho 1983, Burström and Fredlund 2001).

Geocodes were subsequently assigned to local area and suburb administrative units. From this, the 'neighbourhood attribute' spatial measures for urban employment were calculated at the local area or suburb level for each participant using ArcGIS 10.2 (ESRI, Redlands) geographic information systems (GIS) software.

\section{Analysis approach}

The aim of this research was to test direct and pathway associations between selected neighbourhood-level spatial measures of employment with health behaviours and outcomes in an urban population. Accordingly, we constructed two directed acyclic graphs (DAGs) to map hypothesised pathways and temporal contributions between variables (Textor, Hardt et al. 2011). The DAGs are presented in Figures 2 and 3, and guided our analysis plan. In Figure 2, local employment was the exposure variable. In Figure 3, mode access to employment was the exposure variable, with local employment operating as an adjusting variable. All models were adjusted for individual-level sociodemographic confounders, as these were hypothesised to impact on sedentary behaviour (i.e. sex) or self-rated health (i.e. age, marital status, education, income). The conceptual framework suggested the potential importance of 'mode of travel to work' and 'vehicle miles travelled', and 
these were included in the DAGs as latent variables, as these data were not collected in the VicHealth Indicators Survey.

\section{Insert Figures $\mathbf{2}$ and $\mathbf{3}$ about here}

\section{Statistical approach}

All spatial measures were tested for intraclass cluster correlation, and data distributions including residuals were checked prior to collapsing. Multivariate logistic regression models were used to compare the spatial neighbourhood-level employment measures with the likelihood of reporting longer commuting times, longer sitting time, and poorer self-rated health (based on the median splits). Direct and pathway associations were examined. Neighbourhood-level employment analyses were adjusted for sex, age, education, employment, marital status, household income, and clustering at the local area. The mode access to employment models were further adjusted for local employment (as indicated in Figure 3). Analyses were conducted using Stata IC v.13.1, and statistical significance was $\alpha=$ 0.05. Ethical approval for the use of VicHealth Indicators Survey was granted by the Victorian Department of Health and The University of Melbourne Human Ethics Advisory Group.

\section{Results}

Overall, 9,495 respondents in the VicHealth survey lived in urban areas. Of this 5,206 adults were engaged in employment and were included in the following analysis. Table 2 presents the demographic and local area-level profiles for this sample of employed, urban Victorian residents. There were slightly more women (56.2\%) than men in this sample, with the majority aged 35 years or older $(83.7 \%)$. The sample reported high levels of better self-rated health (88.5\%). The median self-reported total employment-related commuting time per day was 45 minutes, and the median time for sitting during a typical weekday was six hours. The median percentage of people living and working in the same suburb was nearly $23 \%$. The majority of people within the respondents' local areas commuted to work via private vehicle $($ median $=83 \%)$, followed by public transport $($ median $=15 \%)$. 
Insert Table 2 about here

Those living in areas with higher levels of local employment had approximately $13 \%$ reduced odds of a longer commute time (defined by the median split) compared with those who lived in a local area with lower levels of local employment (OR = 0.87) (Table 3). However, there was no significant difference between the percentage of employed adults who lived and worked in the same suburb with minutes of weekday sitting or self-rated health.

Significant associations existed between mode access to employment and longer commuting time, longer time spent sitting, and poorer self-rated health. The odds of a longer commute time was $20 \%$ greater for those who lived in an area where more people commuted to work by private vehicle (compared with the reference category). Conversely, the odds of having a longer commute was less for those who lived in local areas where more people travelled to work by public transport $(O R=0.85)$ or active travel $(O R=0.80)$, compared with their respective reference categories.

A counter intuitive relationship was shown when the next attribute on the pathway was considered, being the odds of reporting higher or lower sitting times. The odds of reporting longer sitting times was $35 \%$ less for those who lived in a local area where more people commuted to work by private vehicle. Whereas the odds of reporting longer sitting times was $37 \%$ and $32 \%$ greater for those who lived in local areas where more people commuted by public transport or active travel, respectively (compared with their respective reference categories).

The odds of reporting poorer self-rated health were significantly higher for those living in local areas where more people commuted to work by private vehicle $(O R=1.22)$, and significantly lower for those living in local areas where more people commuted to work by public transport $(O R=0.82)$ or active travel $(O R=0.82)$, compared with their respective reference categories.

\section{Insert Table $\mathbf{3}$ about here}


We also wanted to test how the proximal attributes in the proposed pathways were associated, being commuting time and sitting time, and sitting time and self-rated health. Significant relationships were observed (Table 4). Those who had a longer commute times, regardless of travel mode, had $65 \%$ greater odds of reporting more sitting during a typical weekday. In turn, those who spent more time sitting during a typical weekday (based on the median split) had significantly greater odds of reporting poorer self-rated health $(O R=1.34)$.

\section{Insert Table 4 about here}

\section{Discussion}

Our work showed significant associations between neighbourhood-level spatial measures of employment with behaviours, intermediate outcomes, and long-term outcomes as theorised in our conceptual framework. In summary, a high proportion of local employment was associated with reduced commuting time. High proportions of area-level car reliance for commuting to work were associated with longer commuting times and poorer self-rated health. The opposite relationships existed for commuting by public transport or active travel. Longer commute times were associated with longer sitting times, which was related to poorer self-rated health. However, longer overall sitting times (including driving, working at a desk or computer, reading, watching television, and playing computer games) were positively associated with higher proportions of public transport or active travel commuting modes, and negatively associated with higher proportions of commuting to work by private vehicle. Our findings suggest providing local employment opportunities reduces commute times, which will have health benefits by reducing commuting and sitting time. Diverse commuting modes appear to be associated with different benefits, and future research could explore the mechanisms underlying these relationships. However, this work provides further evidence that area-level spatial measures of employment are related with individual-level behaviours and outcomes. Other work (Ivory, Russell et al. 2015) has argued the built environment reflects the social environment, which in turn reflects an individual's behaviours. This research also examined hypothesised pathways, a noted limitation in previous 
employment studies. Our findings build on the work by van Lenthe et al., (van Lenthe, Borrell et al. 2005) where neighbourhood unemployment rates were positively associated with all-cause mortality; however, potential pathways for this relationship were not investigated in this earlier work (van Lenthe, Borrell et al. 2005) and others (Stutzer and Frey 2004, Palmer 2005).

Our findings provide preliminary evidence of the benefits of a sub-regional strategy that provides local employment opportunities, and provision of public transport and active travel infrastructure that facilitates using alternative modes to driving to access workplaces. Increasing the jobs-housing balance across metropolitan sub-regions might also be a useful strategy for reducing inequity by reducing the proportionally higher time spent commuting, particularly for those on low incomes who seek affordable housing on the urban fringe of cities (Schleith and Horner 2014) and are more vulnerable to mortgage and oil stress (Dodson and Sipe 2008). Together these findings reinforce the need for policies and urban planning strategies that support a balance of jobs and housing.

However, our analysis revealed counterintuitive findings for time spent sitting with mode access to work. Those who lived in local areas where more people travelled to work by public transport or active travel were more likely to report longer time spent sitting. This was unexpected, but could be related to the respondents' occupations. During a typical workday, professional and white-collar workers are more likely to be sedentary than blue-collar employees (Schofield, Badland et al. 2005), and professional workers are more likely to live closer to the inner city where higher-skilled jobs are located (Stoll 2005). This can affect commute modes in three ways. One, for professional employees, the distances between home and the workplace may be shorter and therefore appropriate for active travel (Badland, Schofield et al. 2007), or they may be able to access public transport infrastructure, which tends to be more widely available in inner city areas (Florida 2011). Two, inner city areas are typically more walkable than greenfield developments (Giles-Corti, Mavoa et al. 2014). More walkable environments have been associated with higher levels of recreation and transport walking (Witten, Blakely et al. 2012), yet have also been associated with higher levels of self-reported and objectively-measured sedentary behaviour (Van Dyck, Cardon et al. 2010). 
Although not directly measured in this study, areas that have greater jobs-housing balance may have greater mixed land use, which increases the walkability of an area. Three, another explanation for this finding could be that travelling actively or by public transport may reduce opportunities for doing other activities (which in this case may or may not be sedentary), by limiting the time available for engaging in other activities (Singleton 2013).'

Using routinely collected data, we have demonstrated that it is possible to measure and monitor jobs-housing balance and work travel modes across an urban region. In turn, these data will be useful to create area-level employment and commuting indicators. The indicators can then be used by urban and transport planners and local government to identify areas where there is a potential mismatch between employment supply and demand, and to monitor work-related travel behaviours within and between regions of interest. Furthermore, using routinely collected data that are available nationally (such as these census data), enables indicators to benchmark changes within and between cities, and if replicated over time, can monitor progress. This information can be used to help inform future integrated planning decisions across multiple sectors (e.g. transport, housing, infrastructure planning) (Cervero and Duncan 2006).

As supported by our data, automobiles remain by far the dominant commute mode of choice in developed countries (Lyons and Chatterjee 2008, Department for Transport 2013), and this trend is extending to developing countries (United Nations Department of Economic \& Social Affairs 2014). Improving jobs-housing balance will likely be an important lever to supporting active travel modes in the Australian and international context. However, improving the jobs-housing balance will likely have more far-reaching effects. Managing domestic and employment components of people's lives is complex and multi-faceted (Becker and Moen 1999, Dieleman 2001), and for dual-income households, there may be some acceptance around at least one of the income earners having a longer commute (Lyons and Chatterjee 2008), or conversely, sub-optimal employment may be sought closer to home for one caregiver. Indeed, women are more likely to be underutilised in the labour force than men (Australian Bureau of Statistics 2013), and tend to limit their career ambitions to fulfil household duties (Becker and Moen 1999). This is an important social and 
economic issue, whereby employment aspirations are not being met and skillsets are not maximised to their full potential (Rohe, Cowan et al. 2012). Having an appropriate jobs-housing balance across a region will likely become more important in future as household structures are increasingly becoming dual-income earners (Australian Bureau of Statistics 2013).

\section{Limitations}

First, although the conceptual framework identifies three neighbourhood-level employment attributes that are hypothesised as being important for health and wellbeing, we were only able to explore local employment and mode access to employment in this research. We also were unable to test the latent variables we hypothesised in the DAGs. The reason being is that we did not have the appropriate data available to test the plausible pathways identified in the conceptual framework. Furthermore, our outcome data were taken from a secondary source; therefore we were limited in the range of behaviours and outcomes we could test. It could be that other intermediate measures (e.g. sleep deprivation), outcomes (e.g. mental health, subjective wellbeing), or employment type show similar or different associations with urban employment measures. We would suggest that these are investigated in future research. We also relied on cross-sectional data to explore the pathways, and in future these should be tested with longitudinal data to determine causality. However, we were able to identify associations, suggesting the hypothesised models were appropriate. Second, spatial data enables measures to be replicated over time, yet there are limitations of relying on administrative units as the unit of analysis. Using administrative units does not necessarily capture people's neighbourhoods or meaningful destinations (e.g. place of employment). Research has shown people have very different neighbourhood 'shapes' depending on their demographic profile and the built environment attributes available to them locally (Ivory, Russell et al. 2015). Our work was delimited to residential SA1s (local areas) and SA3s (suburbs), yet many participants in our sample lived in one administrative boundary, but were employed in contiguous or further afield administrative units. Third, this paper is less generalizable to occupations that are located outside urban areas (e.g. farming communities, manufacturing hubs located in peri-urban settings), or for those who 
travel to numerous locations during the day as part of their employment (e.g. tradespeople). Indeed, we were unable to assess what types of employment people undertook or the occupations they were employed in, and this may contribute independently to health behaviours and outcomes. However, $85 \%$ of the Australian workforce are employed in an urban setting (Australian Bureau of Statistics 2011); we therefore contend this research has an important role for guiding and informing employment-related urban planning policies in the Australian context. Other limitations include the reliance on self-report population survey data and potential selection bias in the VicHealth survey (non-respondent data were unavailable).

\section{Conclusions}

Using local area- and suburb-level spatial measures we were able to provide further evidence for the associations between local employment availability and mode of access with selected health behaviours and outcomes in an urban context. Plausible pathways for how area-level measures of employment might influence health and wellbeing behaviours were also established and tested using routinely available administrative data. The employment indicators we propose can be applied by planners and policy-makers to identify potential mismatches between urban employment supply and demand, benchmark employment distribution changes within and between cities, and if replicated, can monitor progress towards achieving distributed employment. This work can support policy-makers by providing evidence to can help build the argument about which area-level attributes are needed to support urban employment across a region, and lend weight to the need for integrated planning.

\section{Acknowledgments}

This work was supported by the NHMRC Centre for Excellence in Healthy Liveable Communities (No. 1061404) and The Australian Prevention Partnership Centre (supported by NHMRC, ACT Health, NSW Health, the Australian National Preventive Health Agency (ANPHA), the Hospitals Contribution Fund of Australia (HCF) and the HCF Research Foundation). BGC is supported by an NHMRC Principal Research Fellow Award (No. 1004900). All authors are in part, supported by VicHealth.

\section{Conflict of interest statement}

All authors declare they have no conflict of interest.

\section{References}


Australian Bureau of Statistics (2011). Australian rural profile. Canberra, Australian Bureau of Statistics.

Australian Bureau of Statistics (2011). Australian Statistical Geography Standard (ASGS). Canberra, Australian Bureau of Statistics.

Australian Bureau of Statistics (2011). Census 2011. Canberra, Australian Bureau of Statistics.

Australian Bureau of Statistics (2013). Gender indicators, Australia: Underutilised labour. Canberra, Australian Bureau of Statistics.

Badland, H., M. Davern, K. Villanueva, S. Mavoa, A. Milner, R. Roberts and B. GilesCorti (in press). "Conceptualising and measuring spatial indicators of employment through a liveability lens." Social Indicators Research.

Badland, H., G. Schofield and P. Schluter (2007). "Objectively measured commute distance: Associations with actual travel modes and perceptions to place of work or study in Auckland, New Zealand." Journal of Physical Activity \& Health 4(1): 80-86. Badland, H., C. Whitzman, M. Lowe, M. Davern, L. Aye, I. Butterworth, D. Hes and B. Giles-Corti (2014). "Urban liveability: Emerging lessons from Australia for exploring the potential for indicators to measure the social determinants of health." Social Science \& Medicine 111: 64-73.

Baum, F., A. Ziersch, G. Zhang and K. Osborne (2009). "Do perceived neighbourhood cohesion and safety cohesion contribute to neighbourhood differences in health?" Health \& Place 15(4): 925-934.

Becker, P. and P. Moen (1999). "Scaling back: Dual-earner couples' work-family strategies." Journal of Marriage and the Family 61: 995-1007.

Brownson, R., T. Boehmer and D. Luke (2005). "Declining rates of physical activity in the United States: What are the contributors?" Annual Review of Public Health 26: 421-443.

Burström, B. and P. Fredlund (2001). "Self-rated health: Is it a good predictor of subsequent mortality among adults in lower as well as higher social classes?" Journal of Epidemiology and Community Health 55: 836-840.

Cervero, R. and M. Duncan (2006). "Which reduces vehicle travel more: Jobs-housing balance or retail-housing mixing?" Journal of the American Planning Association 72(4): 475-490.

Colantonio, A. and T. Dixon (2011). Urban regeneration and social sustainability. Best practice for European cities. West Sussex, Wiley-Blackwell.

Department for Transport (2013). National travel survey statistics. London, Department for Transport.

Dieleman, F. (2001). "Modelling residential mobility; a review of recent trends in research." Journal of Housing and the Built Environment 16: 249-265.

Dodson, J. and N. Sipe (2008). Unsettling suburbia: The new landscape of oil and mortgage vulnerability in Australian cities. Urban Research Program, Griffith University. 17.

Florida, R. (2011). The rise of the creative class: Revisited. New York, Basic Books. Frank, L. (2004). "Economic determinants of urban form: Resulting trade-offs between active and sedentary forms of travel." American Journal of Preventive Medicine 27(3S1): 146-153. 
Frank, L., M. Andresen and T. Schmid (2004). "Obesity relationships with community design, physical activity, and time spent in cars." American Journal of Preventive Medicine 27(2): 87-96.

Frank, L. D. and G. Pivo (1995). "Impacts of mixed use and density on utilization of three modes of travel: Single-occupant vehicle, transit, and walking." Transportation Research Record 1466: 44-52.

Giles-Corti, B., S. Mavoa, S. Eagleson, M. Davern, R. Roberts and H. Badland (2014). How walkable is Melbourne? The development of a transport walkability index for metropolitan Melbourne. Melbourne, The University of Melbourne. Ivory, V., M. Russell, K. Witten, C. Hooper, J. Pearce and T. Blakely (2015). "What shape is your neighbourhood? Investigating the micro geographies of physical activity." Social Science \& Medicine 133: 313-321.

Jackson, L. (2003). "The relationship of urban design to human health and condition." Landscape and Urban Planning 64: 191-200.

Kaplan, G. and T. Camacho (1983). "Perceived health and mortality: A nine-year follow-up of the Human Population Laboratory Cohort." American Journal of Epidemiology 117: 292-304.

Kluger, A. (1998). "Commute variability and strain." Journal of Organizational Behavior 19(147-165).

Korsu, E. and S. Wenglenski (2010). "Job accessibility, residential segregation and risk on long-term unemployment in the Paris region." Urban Studies 47: 2279-2324. Kwan, M.-P. (2012). "The uncertain geographic context problem." Annals of the Association of American Geographers 102(5): 958-968.

Levine, J. (1998). "Rethinking accessibility and jobs-housing balance." Journal of the American Planning Association 64: 133-149.

Lowe, M., C. Whitzman, H. Badland, M. Davern, D. Hes, L. Aye, I. Butterworth and B. Giles-Corti (2013). Liveable, Health, Sustainable: What are the key indicators for Melbourne neighbourhoods? Place, Health, and Liveability Research Program, University of Melbourne. Research paper 1.

Lyons, G. and K. Chatterjee (2008). "A human perspective on the daily commute: Costs, benefits, and trade-offs." Transport Reviews 28: 181-198.

Milner, A., A. Kavanagh, L. Krnjacki, R. Bentley and A. LaMontagne (2013). "Arealevel unemployment and job insecurity: Evidence from a longitudinal study conducted in the Australian working age population." Annuals of Occupational Hygiene: 1-10.

Norris, M. (2014). Social housing, disadvantage, and neighbourhood liveability: Ten years of change in social housing neighbourhoods. New York, Routledge.

Palmer, A. (2005). Health of people who travel to work: The effect of time travel and mode of transport on health. Kent, Centre for Health Services Studies, University of Kent.

Rohe, W., S. Cowan and D. Roderiguez. (2012). "Assessing the environmental, economic and social benefit of well-located workforce housing." Social Science Research Network Retrieved 23 August 2012, from

http://dx.doi.org/10.2139/ssrn.2135239.

Schleith, D. and M. Horner (2014). "Commuting, job clusters, and travel burdens." Transportation Research Record 2452: 19-27. 
Schofield, G., H. Badland and M. Oliver (2005). "Objectively measured physical activity in New Zealand workers." Journal of Science and Medicine in Sport 8(2): 143151.

Singleton, P. (2013). A theory of travel decision-making with application for modeling active travel demand. Master of Science, Portland State University.

State Government Victoria (2014). Plan Melbourne. Metropolitan planning strategy 2014. Melbourne, State Government Victoria.

Stoll, M. (2005). "Geographical skills mismatch, job search and race." Urban Studies 42: 695-717.

Strategic Review of Health Inequalities in England post-2010 (2010). Fair society, healthy lives. London, Department of Health.

Stutzer, A. and B. Frey (2004). Stress that doesn't pay: The commuting paradox. Bonn, Institute for the Study of Labor.

Textor, J., J. Hardt and S. Knüppel (2011). "DAGitty: A graphical tool for analyzing causal diagrams." Eoidemiology 5: 745.

Theorell, T. (2000). Working conditions and health. Social Epidemiology. L. Berkman and I. Kawachi. New York, Oxford University Press: 95-117.

United Nations Department of Economic \& Social Affairs (2014). World urbanization prospects: 2014 revision. New York, United Nations.

Van Dyck, D., G. Cardon, B. Deforche, N. Owen, J. Sallis and I. De Bourdeaudhuij (2010). "Neighborhood walkability and sedentary time in Belgian adults." American Journal of Preventive Medicine 39: 25-32.

van Lenthe, F., L. Borrell, G. Costa, A. Diez Roux, T. Kauppinen, C. Marinacci, P. Martikainen, E. Regidor, M. Stafford and T. Valkonen (2005). "Neighbourhood unemployment and all cause mortality: A comparison of six countries." Journal of Epidemiology and Community Health 59: 231-237.

Van Rooy, D. (2006). "Effects of automobile commute characteristics on affect and job candidate evaluations." Environment and Behavior 38(5): 626-655.

Warr, D., P. Feldman, T. Tacticos and M. Kelaher (2009). "Sources of stress in impoverished neighbourhoods: Insights into links between neighbourhood environments and health." Australian and New Zealand Journal of Public Health 33(1): 25-35.

Wen, L., N. Orr, C. Millett and C. Rissel (2006). "Driving to work and overweight and obesity: Findings from the 2003 New South Wales Health Survey, Australia." International Journal of Obesity 30: 782-786.

Western Australian Planning Commission and Department for Planning and Infrastructure (2009). Liveable neighbourhoods: A Western Australian Government sustainable cities initiative. Perth, Western Australian Planning Commission. Wilson, J. (2000). "Volunteering." Annual Review of Sociology 26(215-240). Witten, K., T. Blakely, N. Bagheri, H. Badland, V. Ivory, J. Pearce, S. Mavoa, E. Hinckson and G. Schofield (2012). "Neighbourhood built environment is associated with residents' transport and leisure physical activity: Findings from New Zealand using objective exposure and outcome measures." Environmental Health

Perspectives 120(7): 971-977. 
Figure 1. Conceptual framework and pathways of employment and health and wellbeing, specifying neighbourhood attributes, behaviours, and intermediate and long-term outcomes (modified from Badland, Davern et al., (in press))

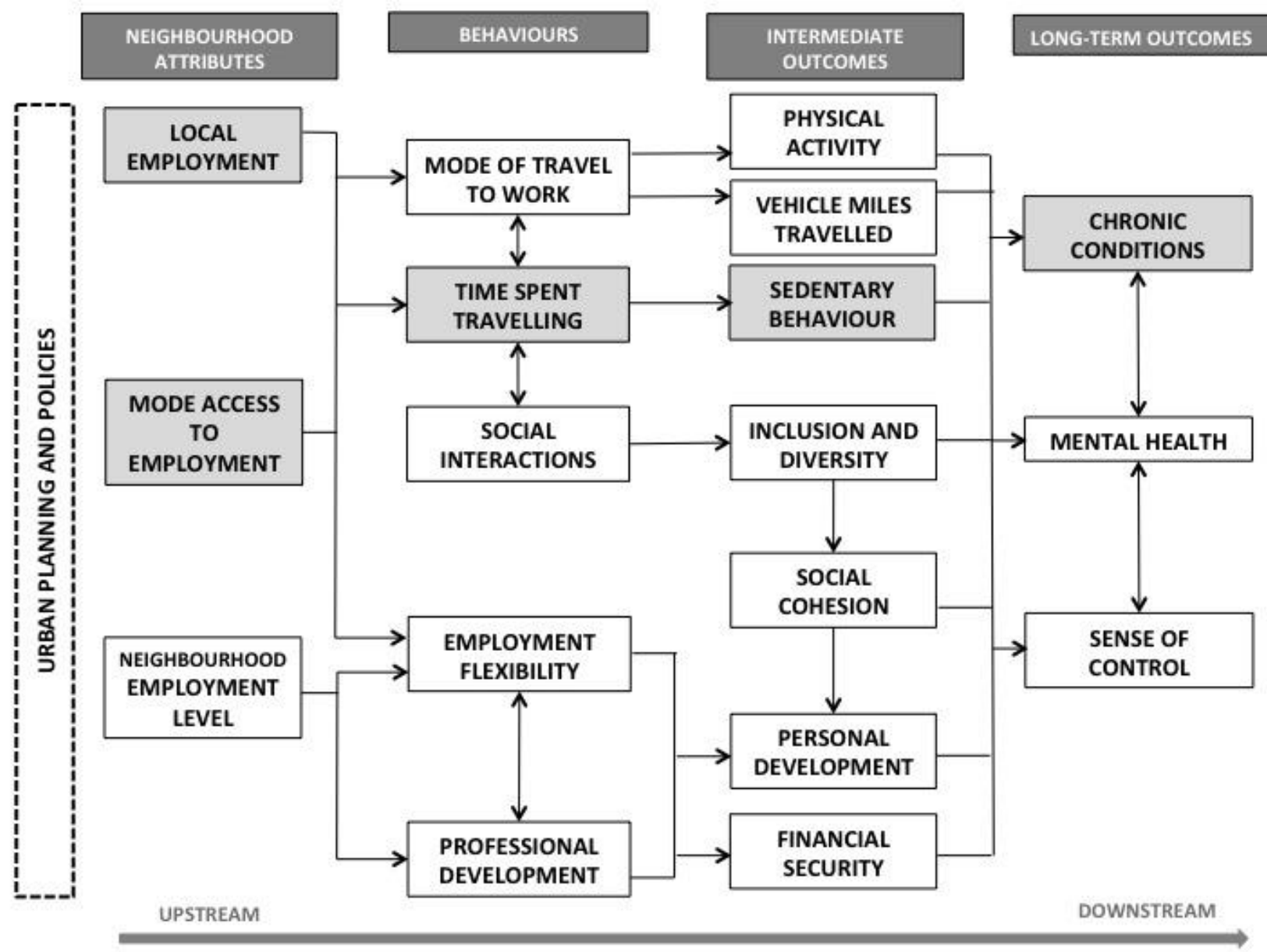


Figure 2. Directed acyclic graph proposing the pathway for how local employment impacts self-rated health

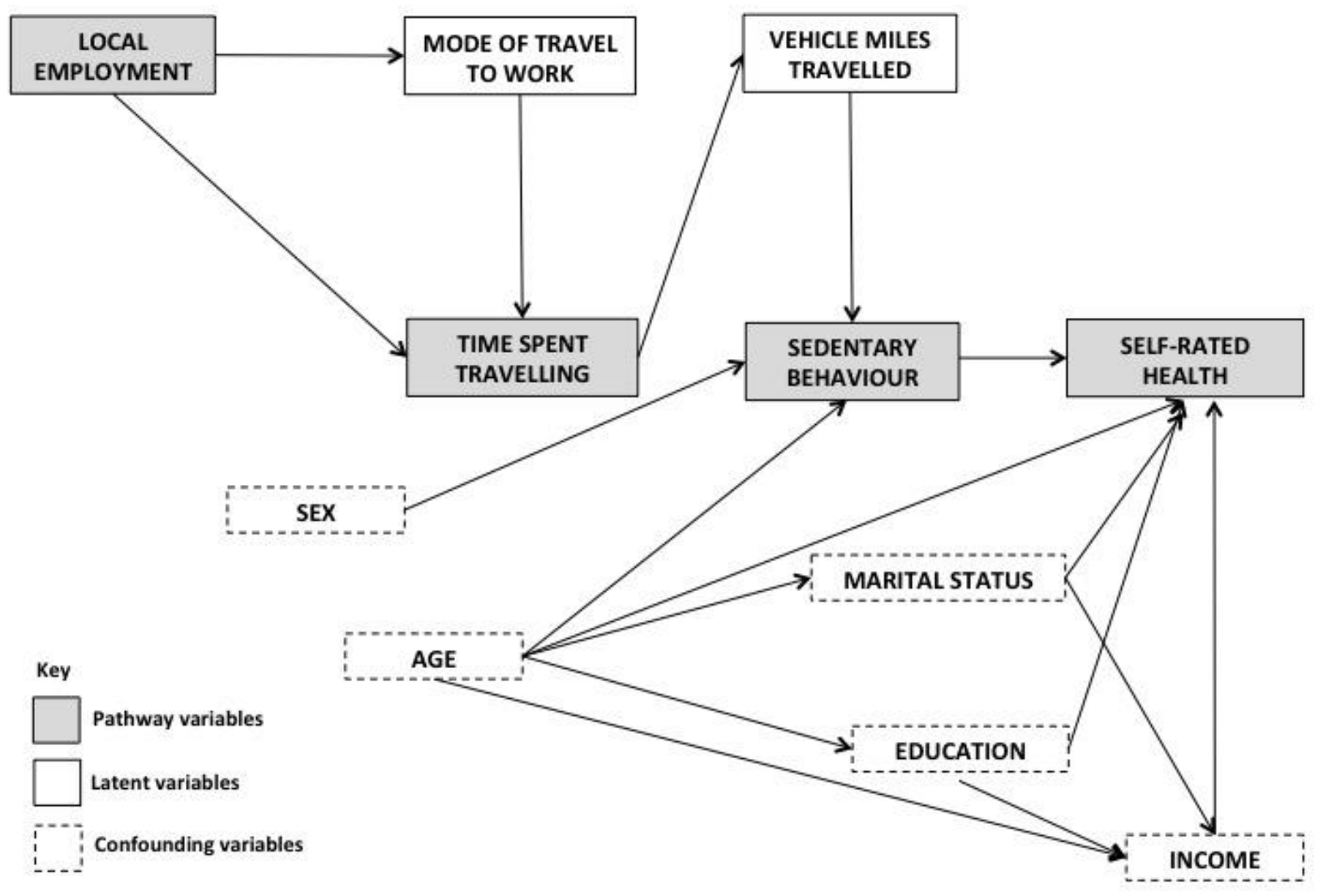


Figure 3. Directed acyclic graph proposing the pathway for how mode access to employment impacts self-rated health

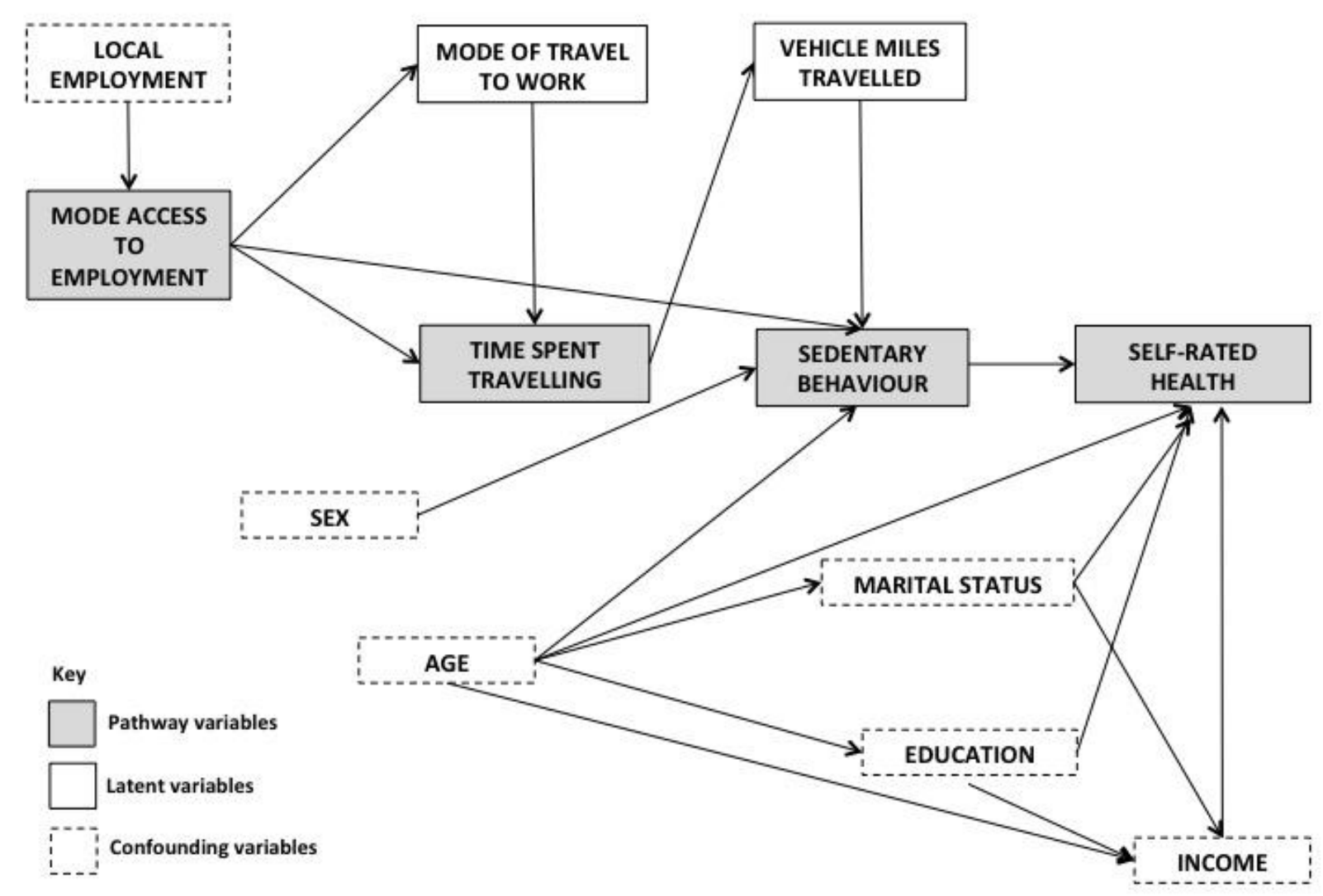

Table 1. Neighbourhood attributes and spatial measures of urban employment

\section{Attribute \\ Local employment}

$\%$ employed adults who lived and worked in the same suburb Mode access to employment

$\%$ employed adults in local area who commuted to work by private vehicle

$\%$ employed adults in local area who commuted to work by public transport

$\%$ employed adults in local area who commuted to work by active travel 
Table 2. Sociodemographic and local area-level profiles for employed adults living in urban, metropolitan areas of Melbourne sampled in the 2011 VicHealth survey

\begin{tabular}{|c|c|c|}
\hline Characteristic & $\mathbf{n}$ & $\%$ \\
\hline \multicolumn{3}{|l|}{$\operatorname{Sex}$} \\
\hline Male & 2,278 & 43.8 \\
\hline Female & 2,928 & 56.2 \\
\hline \multicolumn{3}{|l|}{ Age } \\
\hline $18-34$ years & 850 & 16.3 \\
\hline $35-54$ years & 2,856 & 54.9 \\
\hline$\geq 55$ years & 1,500 & 28.8 \\
\hline \multicolumn{3}{|l|}{ Marital status* } \\
\hline Single & 635 & 12.5 \\
\hline Married / de facto & 3,993 & 78.6 \\
\hline Living with others & 451 & 8.9 \\
\hline \multicolumn{3}{|l|}{ Education qualifications* } \\
\hline$\leq$ High school & 1,653 & 31.9 \\
\hline TAFE / Certificate/ Diploma & 1,091 & 21.1 \\
\hline$\geq$ University & 2,435 & 47.0 \\
\hline \multicolumn{3}{|l|}{ Household income (AUD)* } \\
\hline$<\$ 40,000$ & 672 & 12.9 \\
\hline$\$ 40,000-\$ 79,999$ & 1,449 & 27.8 \\
\hline$\$ 80,000-\$ 119,999$ & 1,161 & 22.3 \\
\hline$\geq \$ 120,000$ & 1,091 & 21.0 \\
\hline \multicolumn{3}{|l|}{ Self-rated health } \\
\hline Poorer & 599 & 11.5 \\
\hline Better & 4,605 & 88.5 \\
\hline \multicolumn{3}{|c|}{$\begin{array}{l}\text { Daily commute time to and from place of employment } \\
\text { (minutes) }\end{array}$} \\
\hline Median (min, $\max$ ) & 45.0 & $(1.00,360.00)$ \\
\hline \multicolumn{3}{|c|}{ Time spent sitting during a typical weekday (minutes) } \\
\hline Median (min, $\max$ ) & 360.0 & $(1.00,1,440.00)$ \\
\hline \multicolumn{3}{|c|}{$\begin{array}{l}\text { \% employed adults in local area who lived and worked in } \\
\text { the same suburb }\end{array}$} \\
\hline Median (min, $\max )$ & 22.8 & $(11.77,56.60)$ \\
\hline \multicolumn{3}{|c|}{$\begin{array}{l}\% \text { employed adults in local area who commuted to place of } \\
\text { employment by private vehicle }\end{array}$} \\
\hline Median (min, $\max$ ) & 82.5 & $(0.00,100.00)$ \\
\hline \multicolumn{3}{|c|}{$\begin{array}{l}\% \text { employed adults in local area who commuted to place of } \\
\text { employment by public transport modes }\end{array}$} \\
\hline Median (min, $\max$ ) & 15.1 & $(0.00,100.00)$ \\
\hline \multicolumn{3}{|c|}{$\begin{array}{l}\% \text { employed adults in local area who commuted to place of } \\
\text { employment by active travel modes }\end{array}$} \\
\hline Median (min, $\max$ ) & 2.7 & $(0.00,100.00)$ \\
\hline
\end{tabular}

Table notes

* Does not add to total $\mathrm{n}$ because of missing values

Key: $A U D=$ Australian dollars; $\max =$ maximum $; \min =$ minimum; $\%=$ percentage 
Table 3. Associations between local employment and mode access to employment with commuting time to work, time spent sitting, and self-rated health for employed adults living in urban, metropolitan areas of Melbourne sampled in the 2011 VicHealth survey

\begin{tabular}{|c|c|c|c|c|c|c|c|c|c|}
\hline & \multicolumn{3}{|c|}{$\begin{array}{l}\text { Model I: Longer commute time to } \\
\text { and from work } \\
\text { (median split) }\end{array}$} & \multicolumn{3}{|c|}{$\begin{array}{l}\text { Model II: Longer time spent sitting } \\
\text { during a typical weekday } \\
\text { (median split) }\end{array}$} & \multicolumn{3}{|c|}{$\begin{array}{c}\text { Model III: Poorer self-rated } \\
\text { health }\end{array}$} \\
\hline & OR & $95 \% \mathrm{Cl}$ & p-value & OR & $95 \% \mathrm{Cl}$ & p-value & OR & $95 \% \mathrm{Cl}$ & p-value \\
\hline \multicolumn{10}{|c|}{$\begin{array}{l}\% \text { employed adults in local area who lived and worked } \\
\text { in the same suburb (median split) }\end{array}$} \\
\hline Lower & 1.00 & - & & 1.00 & - & & 1.00 & - & \\
\hline Higher & 0.87 & $0.77-0.98$ & 0.02 & 1.00 & $0.89-1.13$ & 0.95 & 0.92 & $0.77-1.11$ & 0.39 \\
\hline \multicolumn{10}{|c|}{$\begin{array}{l}\text { Neighbourhood attribute: Mode access to employment } \\
\text { \% employed adults in local area who commuted to place } \\
\text { of employment by private vehicle (median split) }\end{array}$} \\
\hline Lower & 1.00 & & & 1.00 & - & & 1.00 & - & \\
\hline Higher & 1.20 & $1.06-1.36$ & 0.004 & 0.65 & $0.57-0.73$ & $\leq 0.001$ & 1.22 & $1.00-1.49$ & 0.05 \\
\hline \multicolumn{10}{|c|}{$\begin{array}{l}\text { \% employed adults in local areas who commuted to } \\
\text { place of employment by public transport modes } \\
\text { (median split) }\end{array}$} \\
\hline Lower & 1.00 & - & & 1.00 & - & & 1.00 & - & \\
\hline Higher & 0.85 & $0.75-0.96$ & 0.008 & 1.37 & $1.21-1.55$ & $\leq 0.001$ & 0.82 & $0.67-1.00$ & 0.05 \\
\hline \multicolumn{10}{|c|}{$\begin{array}{l}\% \text { employed adults in local area who commuted to place } \\
\text { of employment by active travel modes (median split) }\end{array}$} \\
\hline Lower & 1.00 & - & & 1.00 & - & & 1.00 & - & \\
\hline Higher & 0.80 & $0.71-0.90$ & $\leq 0.001$ & 1.32 & 1.17-1.49 & $\leq 0.001$ & 0.82 & $0.68-1.00$ & 0.05 \\
\hline
\end{tabular}

Table notes

${ }^{\S}$ Models adjusted for sex, age, marital status, education attainment, household income, and clustering at local area

${ }^{\mathscr{H}}$ Model adjusted for sex, age, marital status, education attainment, household income, local employment, and clustering at local area

Bolded text indicates $\alpha=0.05$

Key: $\mathrm{Cl}=$ confidence interval; $\mathrm{OR}=$ odds ratio; $\%$ = percentage 
Table 4. Associations between commuting time to work and time spent sitting, and time spent sitting and self-rated health for employed adults living in urban, metropolitan areas of Melbourne sampled in the 2011 VicHealth survey

\begin{tabular}{|c|c|c|c|c|c|c|}
\hline & \multicolumn{3}{|c|}{$\begin{array}{l}\text { Model I: Longer time } \\
\text { spent sitting during } \\
\text { a typical weekday } \\
\text { (median split) }\end{array}$} & \multicolumn{3}{|c|}{$\begin{array}{l}\text { Model II: Poorer } \\
\text { self-rated health }^{\S}\end{array}$} \\
\hline & OR & $95 \% \mathrm{Cl}$ & $\begin{array}{l}\mathrm{p}- \\
\text { value }\end{array}$ & OR & $95 \% \mathrm{Cl}$ & $\begin{array}{l}\mathrm{p}- \\
\text { value }\end{array}$ \\
\hline \multicolumn{7}{|c|}{$\begin{array}{l}\text { Daily commute time to and from place of } \\
\text { employment (minutes) (median split) }\end{array}$} \\
\hline Lower & 1.00 & - & & & & \\
\hline Higher & 1.65 & $\begin{array}{l}1.46- \\
1.87\end{array}$ & $\begin{array}{l}\leq \\
0.001\end{array}$ & & & \\
\hline \multicolumn{7}{|c|}{$\begin{array}{l}\text { Intermediate outcome: Sitting time } \\
\text { Time spent sitting during a typical weekday } \\
\text { (minutes) (median split) }\end{array}$} \\
\hline Lower & & & & 1.00 & - & \\
\hline Higher & & & & 1.34 & $\begin{array}{l}1.11- \\
1.62\end{array}$ & $\leq$ \\
\hline
\end{tabular}

Table notes

${ }^{\S}$ Models adjusted for sex, age, marital status, education attainment, household income, and clustering at local area

Bolded text indicates $\alpha=0.05$

Key: $\mathrm{Cl}=$ confidence interval; $\mathrm{OR}=$ odds ratio 